\title{
Factors in Managing Organizational Effectiveness: The Case of Iran's Economy
}

\author{
${ }^{1}$ Safdari Mehdi, ${ }^{2}$ Kakoi Mosa* \\ ${ }^{1}$ Department of Economics, University of Qom, Iran \\ 2Department of Management, Qaemshahr Branch, Islamic Azad University, Qaemshahr, Iran \\ *kakoi.manager@gmail.com
}

\begin{abstract}
Today, the most important element of economic is management and here, looking scholars management is the process in efficient use of resources therefore being numerous human and material resources are useable. Money and capital are important factor in the economy but when this factor is satisfactory that be managed optimal way also human and software resources are important factor in the economy but when these factors are useful that be managed optimal way. The aim of the study is to determine the relationship between leadership styles of managers with organizational commitment that staff are under their supervision and productivity in the Iran's economy in a sample and also investigated some demographic characteristics associated with leadership style variables of managers and staff organizational commitment. Stationary or non stationary variables were analyzed by Augmented Dickey Fuller (ADF) and in order to analyze the data, is used analysis of variance and regression analysis.
\end{abstract}

Keywords: Augmented Dickey Fuller (ADF), Transformational leadership, transactional, laissez-faire and Regression correlation

\section{Introduction}

Speed changes and require the use of new ideas is the most important feature of administrative systems in the effective management activities and efficient organization and employees of any organization, are the most valuable asset due to the ideas, thoughts and creativity. Management's ability to conform and adapt to new situations depends on management practices and innovative new ways in a position to act on behalf of the conditions and factors. Change in circumstances is not enough continue past based on past experience only and continuous organization needs to new ideas and creative thinking. This view has led to survey and study behavior leadership and effect on the employee attitudes and behaviors including organizational commitment in recent years. Based on the results of some research conducted in this connection Committed employees could lead to more effort and strong desire to maintain organization. More research emphasized to the behavior leadership and organizational outcomes on task oriented leadership styles. In addition some researchers believe that situational approaches to leadership was replaced instead of these approaches that does not attention to many situations including how the perception of subordinates from leader and relationship quality leader - follower. According to some scholars believed so that new leadership approaches can be more favorable effect on attitudes and behavior of followers. It seems that managers can increase promise and commitment employees by new research findings and adopting leadership styles based on management science. By the same token, one of the latest theories of transformational and transactional leadership that has the more integrity has emerged interest and attention of many experts and knowledge management experts. transactional leadership depends on transactional between leader and subordinates and is believed to motivate followers to increase due to exercise contingency rewards while transformational leadership depends on emotional and personal relationships between leader and subordinates and focuses on the stimulate followers in order to yield more than what is expected. Based on more researchers new behavior leadership has an effective role in increasing the motivation of followers to work.

This research questions there is significant correlation between transformational, transactional and laissez-faire leadership style of managers with Organizational commitment that staff are under their supervision? Organizational commitment data is collected by an Organizational Commitment Questionnaire (OCQ) and leadership styles, determining Warner's transformational and transactional leadership and also Bardnes laissez-faire leadership. Personal information collected by questionnaire and individual characteristics. Statistical population the study included all employees and managers that their number is equal to 137 and was selected sample of people to do a preliminary study equal to 35 and didn't go out of the entire statistical community. All questionnaires were sent back of their 137 total. 
Leadership Style: About of leadership definition have proposed different opinions from management experts so that the first theory is based on trait theory of leadership. Studies and basic research are based on the assumption that leaders are born with traits transactional due to inadequate theories, failure in many of the traits measured and failure in detecting possible differences in organizations and also was not very successful. The second theory is the behavioral theories and assumes that leadership is axis function and maintains human resources. In this case are considered behaviors transactional or actions instead of emphasis to the main characteristics and human skills instead of technical skills. Other theories are theories of leadership position and they insist on the ability acquired or potential leadership on the behavior observed and also these theories are based on behavior of leaders and their staff in different positions. Situational leadership theorists try to determine the appropriate leadership style in various situations and believe that most people can increase their ability in leadership roles by education, training and development while another theory states that one kind of process-transactional approach was created from the perspective of social transactional into leadership issue.

This approach focuses on the social transactional between leader and subordinates during time including the mutual influence and the personal perception. transactional approach believes that the leader has the benefit for subordinates for example makes clear to them the position and orientation instead, subordinates are allowed to respect and esteem to the leader and are ready to execute his orders. This transactional approach is consistent with other contemporary views of social science that more emphasis is on importance of persuasive influence in leadership in organizations. In this regard Greene (1993) develop some kind of the transactional model leader for relations leader with slave that focuses on the role of leader and subordinates and in summary, the transactional leadership model be allowed to distinguish between subordinates that are closer and farther to the leader in this way that those who are closer to leader have better quality relationships leader instead leader is expected of them in terms of performance and loyalty.

Transactional Leadership: Transactional leadership is required to sub-leader relationship that subset receives performance-related bonuses to himself expectations in exchange announced by the leader. Communicate this type of leadership is done by contingency rewards and management based on exceptions to the subset. Contingency reward means that leader will provide various types of rewards towards achieving the agreed objectives. Accordingly contingency reward is active behavior in transactional leadership. Exception based in the management (active and passive), active leader is careful to specifically and will search the deviation from the objectives while passive leader is waiting to see happen in the future. Accordingly transactional leadership for implementation is based on two component functions including contingency reward and exception based Management.

Transformational Leadership: Transformational leadership is part of the new paradigm of leadership and tells a process that will change the people and it is associated with values, ethical features and longterm goals. This type of leadership functions is including evaluation of stimuli effective followers, meet their needs and treat with them as full persons. Transformational leaders induce a vision to followers that inspire followers and raise them to achieve something extraordinary or beyond the expected and more importantly, accept and understand it as their own views and aspirations. Being a practical transformational leadership requires the four factors as elements of this theory including:

- Individualized consideration: Leader treats followers and their subsets as a trainer and training provider, promotes them, delegation to them and will deal with them according to their merit.

- Intellectual stimulation: Leader encourages the thinking space and people are forced to think and reason before acting.

- Inspirational motivation: Leader provides hope in the subset, defines the future vision clear and achievable and encourages people to raise their expectations.

- Idealized influence or charisma: Leader show self sacrifice, is receptive and is responsible for his actions, people can share in the joy and in practice shows that is crucial.

Also other research shows that transactional leadership is not frustrating or cause discontent followers necessarily but is more frustrating and because of less satisfying followers than transformational leadership. Features transformational leaders are confidence, positive thinking, conviction, having high expectations and building confidence in subordinates. Forming the main component transformational and transactional leadership shown in figure 1 below: 
Figure 1. Forming the main component transformational and transactional leadership

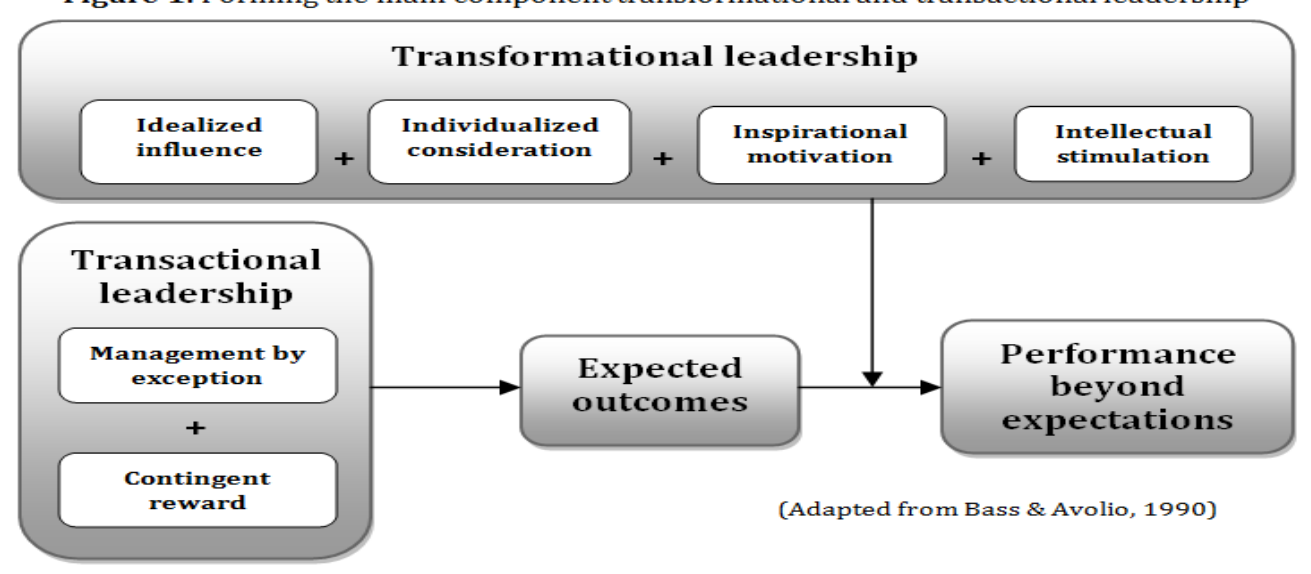

Organizational commitment: Organizational commitment is one of the most important motivational issues that today are noted in the sheer volume of research related to the organizational behavior because one of the an indicator of excellence of an organization to other organizations is having committed human resources. Although different definitions of commitment can be found in the literature but each of them are expressed overall three themes including affective commitment, continuance commitment and normative commitment (Meyer, Allen and Smith, 1993).

- Affective commitment: Most general way to deal with organizational commitment is the way to be considered as emotional and psychological attachment to organization. On this basis a person who is highly committed, to identify himself with the organization, will participate in the organization and be involved in that and enjoyed membership in the organization.

- Continuance commitment: Some experts believe that affective and mental attachment no less prominent role in the concept of commitment instead commitment is defined as the desire to perform continuous activity according to recognize and understand individual than the costs resulting from leaving the organization. On this basis, whatever a person thinks the high cost of leaving the organization thus will be more interested to stay in the organization and commitment.

- Normative commitment: Normative commitment is affected by the personal experience before entering the organization (family socialization) and after entering the organization (organizational socialization). Family socialization means that when a person have strong normative commitment that his views of important people such as parent have been emphasized to an organization or themselves have been long employed in that organization. Also organizational socialization means that staffs by different methods of organization are guided to the location where they can understand and believe organization very well.

Three component conceptualization of organizational commitment shown in figure 2 below (Meyer \& Allen, 1991):

Figure 2: A three component model of organization commitment

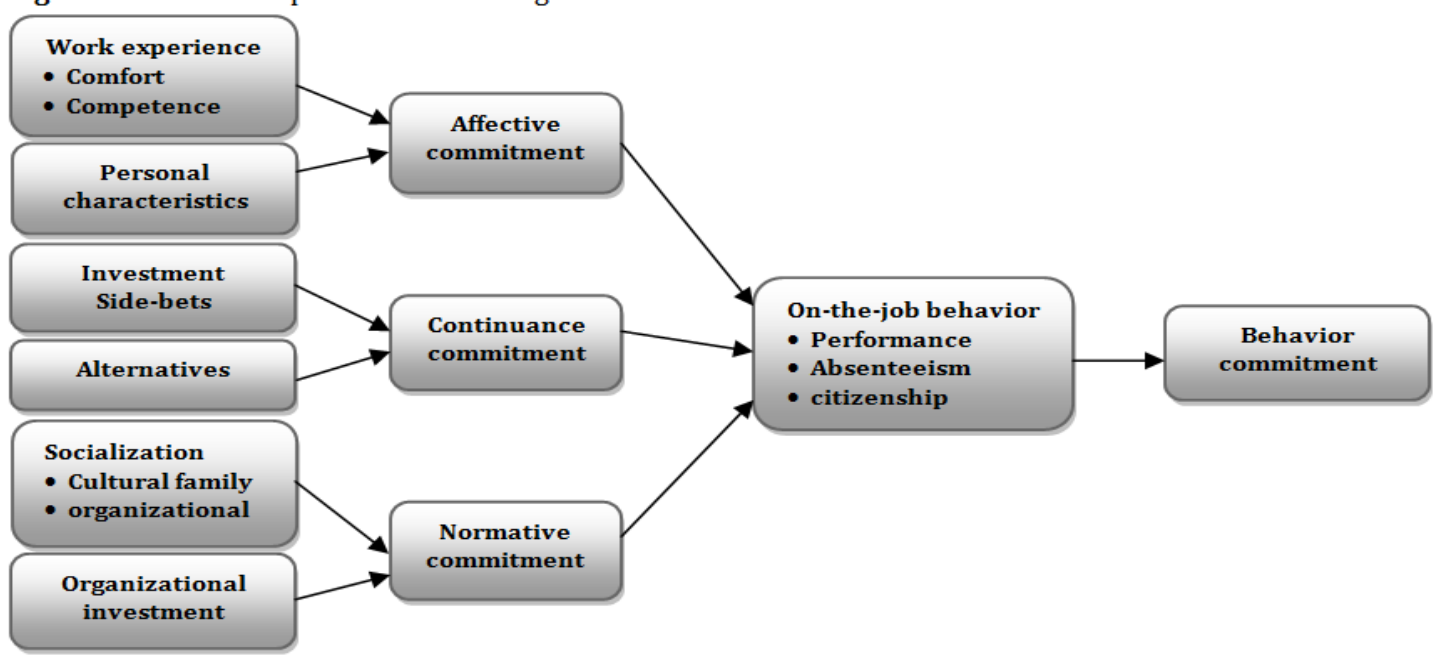




\section{The Previous Studies}

Bycio, Hackett and Allen (1995) have studied to the transformation and behaviors leadership and organizational commitment of staff. They concluded that all aspects of development leadership are associated with emotional commitment and organizational commitment proposed by Allen \& Meyer (1996). Also, their findings show there is no significant relationship between intellectual stimulation dimensions in transformation leadership and commitment to Task, while there is a positive relationship between dimensions of individual attention and leadership in transformation leadership and emotional and Task commitment (Branch, 1990). Wesse (1995) has done a research as the relationship between leadership and corporate culture with sports Managers in amount of ten universities in America and nine sports conference. Analysis of results using statistical method of the Analysis Of Variance (ANOVA) showed that up and down transformation leadership has no effect on organization effectiveness but has a strong relationship with corporate culture. Positive corporate culture increase follower commitment to the organization and in confirmation of this story, Martin (1985) has suggested that corporate culture is an important key to increasing employee commitment to the organization.

Organ (1988) has reviewed empirical research which demonstrates that employee job satisfaction is an important determinant of extra-role (e.g. "organizational citizen-ship") behavior. Hackett (1995) reviewed the relationship between transformation and transactional leadership and follower commitment to the organization and concluded that there is a strong relationship between all dimensions of transformation leadership and emotional commitment but did not obtain a significant relationship between transactional leadership and organizational commitment. Smith, Organ and Near (1983) found that employee satisfaction mediated the impact of leader supportiveness on employee altruism. Followers' trust in and loyalty to the leader also has been accorded a similar role in several recent discussions of the transformational leadership process. Thus, both followers' trust and satisfaction have been identified as potential mediators of the impact of transformational leader behaviors on followers' citizenship behaviors.

\section{Methodology}

Generally, goal of this research is the survey relationship between transformational, transactional and laissez-faire leadership style of managers with organizational commitment that staffs are under their supervision in this sample and its relationship with some individual characteristics of managers and employees. Used methods in this study are descriptive and correlation models and data collection was performed by field studies as have used the reliable and standard questionnaire with stationary variables. In this study, statistical population and sample are including staff and managers in statistical sample in 2005 year that in total are 137 people. Of this number have considered 15 manager and 20 employees for preliminary study because go up the validity of this research with all members of population. Of this number, people in the statistical population responded 29 managers and assistants the questions related to leadership styles and responded 108 staff under their supervision to the questions related to organizational commitment. The research variables are including:

- Predictor variable: transformational, transactional and laissez-faire leadership styles

- Criterion variable: Organizational commitment

- Damper variable: Individual characteristics (Age, qualification, field of study, job experience, average salaries and marital status)

For the analysis of data has used two methods descriptive and inferential statistic. We used descriptive statistic in order to organizing, summarize, classification of raw scores, setting the frequency distribution table and computing scatter parameters and also we used inferential statistic because according to research objectives.

\section{Results}

We divide this chapter into two parts; the first part is descriptive statistics means that describing the statistical including frequency and percentage of individual properties ${ }^{1}$ managers and staff under their supervision and also is mentioned to statistical indicators related to scores of managers leadership styles

${ }^{1}$ Such as age, work experience, qualification, field of study, marital status, average salaries 
and managers organizational commitment. In the second part first, second and third hypotheses are tested by Spearman correlation coefficient. Describe the individual characteristics related to staff under manager's supervision is shown in the tables below.

Table 1: Frequency of Population under Investigation

\begin{tabular}{cccccc}
\hline & & Frequency & percent & $\begin{array}{c}\text { Credit } \\
\text { percentage }\end{array}$ & $\begin{array}{c}\text { Cumulative } \\
\text { percent }\end{array}$ \\
\hline \multirow{3}{*}{ Sexuality } & Man & 78 & 64.2 & 64.2 & 64.2 \\
& Woman & 32 & 35.8 & 35.8 & 100 \\
& Total & 110 & 100 & 100 & - \\
\hline & Non-office & 84 & 65.2 & 84.6 & 84.6 \\
Field of & related & & & & \\
study & office concerned & 28 & 12.6 & 15.4 & 100 \\
& Total & 112 & 77.8 & 100 & - \\
& Missing data & 9 & 22.2 & - & - \\
& Total & 121 & 100 & - & - \\
\hline \multirow{3}{*}{ marital } & Single & 22 & 71.8 & 71.8 & 71.8 \\
status & Married & 78 & 28.2 & 28.2 & 100 \\
& Total & 100 & 100 & 100 & - \\
& $20-25$ & 32 & 28.6 & 29 & 26.1 \\
Age & $25-30$ & 28 & 22.1 & 22.5 & 34.3 \\
workers & $30-35$ & 19 & 18.6 & 18.8 & 22.1 \\
& 35-40 & 12 & 12.2 & 13 & 17.5 \\
& 40 and above & 11 & 16.2 & 16.7 & 100 \\
& Total & 102 & 97.7 & 100 & - \\
& Missing data & 3 & 2.3 & - & - \\
\hline & Total & 105 & 100 & - & - \\
\hline
\end{tabular}

Spearman Correlation Coefficient Test: In Spearman test the first hypothesis is that there is no significant relationship between transformational leadership style manager's employees with organizational commitment. The second hypothesis that there is no significant relationship between transactional leadership styles of managers with organizational commitment that staffs are under their supervision. Third, there is a significant relationship between laissez-faire leadership styles of managers with organizational commitment that staffs are under their supervision. Results of Spearman correlation coefficient test by the first and second and third hypothesis are shown below:

Table 2: Indicators related to the manager's leadership styles in the population under investigation

\begin{tabular}{|c|c|c|c|c|c|c|c|}
\hline & \multirow[t]{2}{*}{ No } & \multirow[t]{2}{*}{ Min } & \multirow[t]{2}{*}{ Max } & \multirow[t]{2}{*}{ Mean } & \multirow{2}{*}{$\begin{array}{c}\text { Std } \\
\text { Error }\end{array}$} & \multicolumn{2}{|c|}{ Organizational Commitment } \\
\hline & & & & & & $\begin{array}{c}\text { Spearman } \\
\text { correlation }\end{array}$ & $\begin{array}{c}\text { Significant } \\
\text { level }\end{array}$ \\
\hline $\begin{array}{l}\text { Laissez-faire } \\
\text { leadership }\end{array}$ & 23 & 18 & 20 & 13.4 & 3.54 & 0.154 & 0.356 \\
\hline $\begin{array}{l}\text { Transformational } \\
\text { leadership }\end{array}$ & 21 & 16 & 31 & 25.6 & 4.32 & 0.332 & 0.095 \\
\hline $\begin{array}{l}\text { Transactional } \\
\text { leadership }\end{array}$ & 28 & 19 & 29 & 27.2 & 4.02 & -0.492 & 0.002 \\
\hline
\end{tabular}

\section{Conclusion, Discussion and Recommendation}

Discussion: According to the results of first hypothesis ( $r=0.418$ ), there is a positive and significant relationship between manager's transformational leadership and staff's organizational commitment are under their supervision and also this hypothesis is rejected at significant level 5 percent. It means that whatever increase manager's transformational leadership, staff's organizational commitment that is under their supervision increases equally. According to the results of second hypothesis $(r=-0.584)$, there is a negative and significant relationship between manager's transactional leadership and staff's organizational commitment are under their supervision and also this hypothesis is rejected at significant level 5 percent. It means that whatever increase manager's transactional leadership, staff's 
organizational commitment that is under their supervision decreases equally. According to the results of third hypothesis, there is no significant relationship between manager's laissez-faire leadership and staff's organizational commitment that are under their supervision and also this hypothesis is not rejected at significant level 5 percent. It means that manager's laissez-faire leadership no significant effect on rate of staff's organizational commitment that is under their supervision.

Summary and Recommendation: The results of statistical analysis can be concluded that whatever increase manager's transformational leadership, staff's organizational commitment that are under their supervision increases and can be concluded that whatever increase manager's transactional leadership, staff's organizational commitment that are under their supervision decreases and also other result is that there is no significant relationship between manager's laissez-faire leadership style and staff 's organizational commitment that are under their supervision. Based on research hypotheses, since in most cases communications transformational leadership has been strong than transactional and laissez-faire leadership and manager's relationship style lead to more organizational commitment in employees who are under the supervision, it seems this kind of leadership style is more appropriate for population under study. According to features such as ensuring respect, trust and admiration for the staff, entrusting to staff and explanation of organizational goals as simple and clear, transformational leadership style can be change expectations of his followers and can be stimulate them to the performance is more than expected.

Since the present study has analyzed the relationship between leadership styles and organizational commitment, is recommended that similar researches will done with the other leadership styles and organizational behavior including job satisfaction, organizational culture, job performance and etc in order to clarify the relationship between them.

\section{References}

Allen, N., J. \& Meyer, J., P. (1996). Affective, continuance, and normative commitment to the organization: An examination of construct validity. Journal of Vocational Behavior, 49(3), 252-276.

Bass, B., M. \& Avolio, B., J. (1990). The implications of transactional and transformational leadership for individual, team, and organizational development. Research in Organizational Change and Development, 4, 231-272.

Bycio, P., Hackett, R., D. \& Allen, J., S. (1995). Further assessments of Bass's (1985) conceptualization of transactional and transformational leadership. Journal of Applied Psychology, 80, 468-478.

Greene, M. B. (1993). Chronic exposure to violence and poverty: Interventions that work for youth. Crime and Delinquency, 39, 106-124.

Hackett, R., D. (1995). Exploring organizational commitment following radical change: A case study within the Parks Canada Agency [dissertation]. Canada: University of Waterloo.

Branch, D. (1990). Athletic director and selected subordinate perceptions of leadership behavior as predictors of athletic organizational effectiveness. Journal of Sport Management, 4(2), 161-173.

Martin, M., J. (1985). A seminar to prepare students for the professional world. Journal of college student personnel, 26, 177-178.

Meyer, J., P. \& Allen, N., J. (1991). A three-component conceptualization of organizational commitment: Some methodological considerations. Human Resource Management Review, 1, 61-98.

Meyer, J., P., Allen, N., J. \& Smith, C., A. (1993). Commitment to Organizations and Occupations: Extension and Test of a Three, Component Conceptualization. Journal of Applied Psychology, 78(4), 538-551.

Organ, D., W. (1988). A restatement of the satisfaction-performance hypothesis. Journal of management, $14,547-557$.

Smith, C., A. Organ, D., W. \& Near, J., P. (1983). Organizational citizenship behavior: Its nature and antecedents. Journal of Applied Psychology, 68, 653-663.

Spearman, C. (1904). The proof and measurement of association between two things. The American Journal of Psychology, 15(1), 72-101

Wesse, J. (1995). Transformational leadership in the review system of the country [dissertation]. Tehran: Allame Tabatabaei University. 